\title{
Laparoscopic Cholecystectomy in Situs Inversus Totalis
}

\author{
Falak Sher Malik1, Usman Ismat Butt², Wasim Hayat Khan², Syed Muhammad Bilal2, \\ Muhammad Umar² and Said Umer ${ }^{3}$ \\ 1Department of Surgery, Lahore General Hospital, Lahore, Pakistan \\ 2 Department of Surgery, Services Hospital, Lahore, Pakistan \\ ${ }^{3}$ Department of Surgery, National Hospital and Medical Center, Lahore, Pakistan
}

\begin{abstract}
Situs inversus is a rare condition. It is characterised by reverse handed positioning of the internal viscera. Laparoscopic cholecystectomy is the standard procedure for cholelithiasis, but it may lead to technical difficulties in case of situs inversus, especially to right-handed surgeons. A 40-year female presented to the department with epigastric pain and bloating usually after fatty meals. Diagnosis of symptomatic gall bladder stone was made. She was a known case of situs inversus. Laparoscopic cholecystectomy was performed by right-handed surgeon with uneventful recovery.
\end{abstract}

Key Words: Laparoscopic cholecystectomy, Situs inversus, Right-handed surgeon.

How to cite this article: Malik FS, Butt UI, Khan WK, Bilal SM, Umar M, Umer S. Laparoscopic cholecystectomy in situs inversus totalis. J Coll Physicians Surg Pak 2019; 29(10):1000-2.

\section{INTRODUCTION}

Situs inversus is a rare condition. It involves transposition of major organs. ${ }^{1}$ The major organs usually lie in a position on the opposite side to the normal anatomical position. In humans, it was first reported by Fabrcius in $1600 .^{2}$ Its incidence is reported to be 1 in 10,000 to 20,000 live births. It can be divided into two types. If either thoracic or abdominal organs are involved, it is called situs inversus partialis; but involvement of both is known as situs inversus totalis.

Situs inversus presents a technical challenge during laparoscopic cholecystectomy, especially for right handed surgeons. This is because there is a need for reorientation of the intended surgical site to the left upper quadrant. The presence of other anomalies of the hepatobiliary tree which may lead to operative difficulty and increased risk of injury are associated with the leftsided gall bladder. However, with proper identification of the anatomy, minimally invasive approaches are still considered safe. ${ }^{3}$

\section{CASE REPORT}

A 40-year female patient was admitted via outpatient department (OPD) to Department of Surgery, Lahore General Hospital, with history of episodic epigastric pain and bloating after meals for the past one month. She was a diagnosed case of dextro-cardia. On physical

Correspondence to: Dr. Usman Ismat Butt, Department of

Surgery, Services Hospital, Lahore, Pakistan

E-mail: usmanismatbutt@yahoo.com

Received: November 14, 2018; Revised: March 03, 2019;

Accepted: March 28, 2019 examination, abdomen was found to be soft with mild tenderness on palpation in left subcostal area (positive left-sided Murphy's sign). She did not have any history of jaundice, fever, chills and diarrhea. She had no significant medical history apart from controlled hypertension.

An electrocardiography, echocardiography and X-ray chest were performed. These showed normal ventricular function and pericardium with anomalous transposition of the organs as situs inversus totalis. Ultrasonography found gallbladder on left side of the abdomen being full of small stones. The cystic duct was long and dilated but common bile duct (CBD) was normal. Routine preoperative workup was done which revealed no abnormalities.

In order to carry out the laparoscopic cholecystectomy, theater setup was changed to a mirror-image of normal settings. Surgeon and first assistant were positioned to the right of the patient; whereas, second assistant and scrub nurse on the left side (Figure 1). Induction of anasthesia was done in routine manner. Patient was placed in supine position. There was slight elevation of the left side.

Pneumo-peritoneum was created keeping abdominal pressure at $14 \mathrm{~mm} \mathrm{Hg}$ using $\mathrm{CO}_{2}$ gas. Four ports were inserted, primary port $(10 \mathrm{~mm})$ in the infra-umbilical position, $2^{\text {nd }}(10 \mathrm{~mm})$ port was inserted at sub-xiphoid position, $3^{\text {rd }}(5 \mathrm{~mm})$ was inserted in mid-clavicular line below costal margins, and $4^{\text {th }}(5 \mathrm{~mm})$ was inserted in subcostal close to anterior axillary line under direct vision. The $3^{\text {rd }}$ and $4^{\text {th }}$ ports were inserted on the left side (Figure 2). After safe entry, a general survey was made to confirm anomalous mirror imaged transpositions. With gentle dissection, the Calot's triangle was dissected. The 


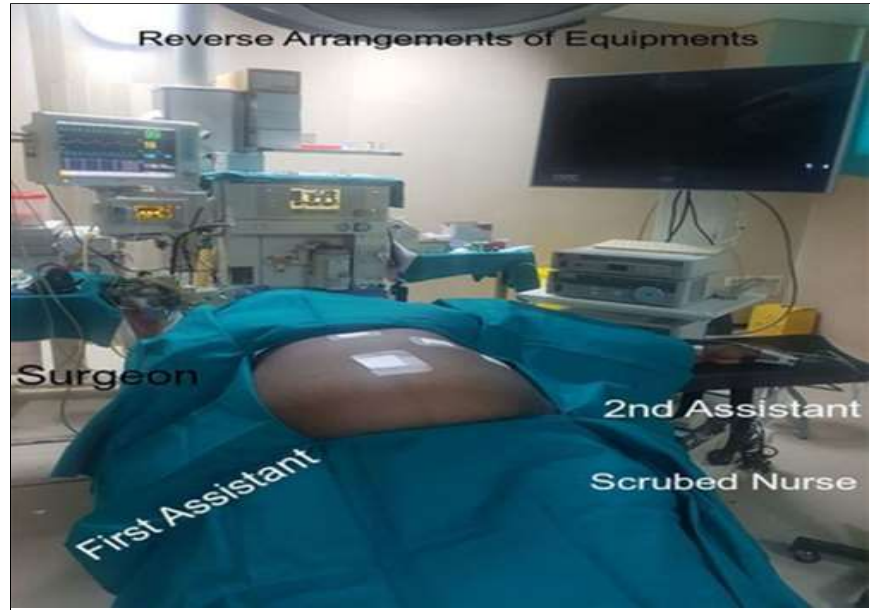

Figure 1: The operation room setup.

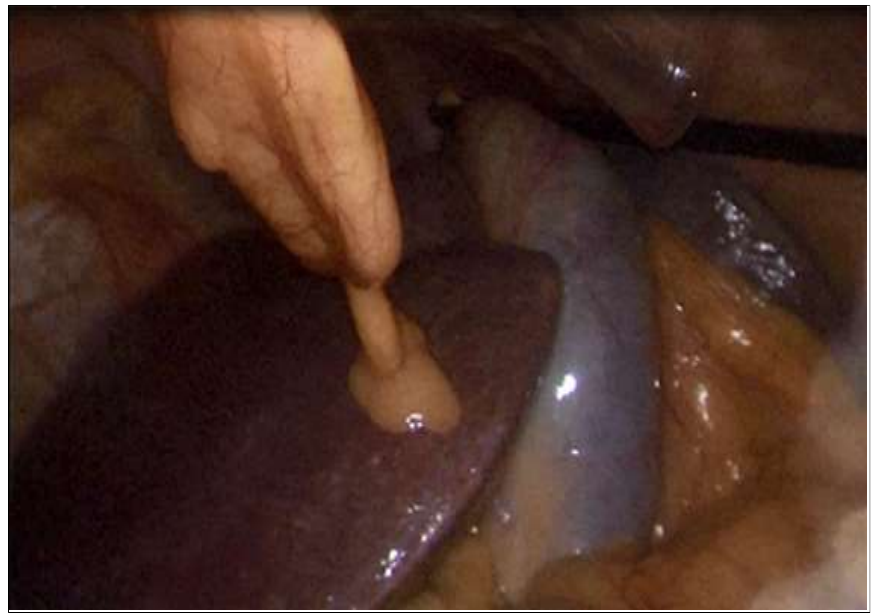

Figure 2: Intraoperative left-sided gall bladder.

umbilical port was used for laparoscope. We made use of the $4^{\text {th }}$ port at the level of anterior axillary line to provide retraction at the fundus. The epigastric port was used primarily to carry out the dissection of Calot's triangle, while the mid clavicular port was used both to provide retraction and help with dissection. Cystic artery and duct were skeletonized. Strasburg view of safety was confirmed before clipping the structures. Gallbladder was dissected out. Hemostasis was secured and gallbladder retrieved from the umbilical port. Drain was placed in the sub-hepatic space. Patient made an uneventful recovery, the drain was removed and she was discharged after 24 hours.

\section{DISCUSSION}

Situs inversus totalis is a rare disorder. It has autosomal, and X-linked inheritance. There is transposition of the thoracic and abdominal viscera through the sagittal plane. It results in a mirror image transposition of normal anatomical structures.

Diagnosis of gall stones in such patients is difficult, especially where previous history is unknown. Pain usually occurs in the left upper quadrant due to the presence of the gallbladder on the left side. However, in $30 \%$ patients it has been reported in the epigastrium; whereas, $10 \%$ patients may present with pain in right upper abdomen. ${ }^{4}$

Laparoscopic cholecystectomy is technically difficult procedure in patients with situs inversus, especially for the right handed surgeons. Campos and Sipes reported the first laparoscopic cholecystectomy in patients with situs inversus in 1991.5

The biggest hurdle faced while performing laparoscopic cholecystectomy in patients with situs inversus is the reversing of the normal anatomy. There is difficulty in orientation and dissection during the procedure. To overcome this issue, several modifications have been proposed. ${ }^{6}$ Right-handed surgeons, Lochman and Arya, made use of an assistant during the surgery to enable grasping and retraction of the infundibulum. ${ }^{4,7}$ Righthand of surgeon was utilised through the epigastric port to perform the dissection.

In this case, the surgeon was right-handed. Operation Room setup, surgeon's position and port placement were mirrored as compared to routine laparoscopic cholecystectomy. The surgeon stood on the right side while primarily making use of the epigastric port for dissection with his left hand and providing retraction at infundibulum via mid-clavicular port by use of right hand. The retraction at fundus was provided by the assistant surgeon through the anterior axillary port.

Only a few other cases have been reported in the literature to date. ${ }^{8}$ To the best of the authors' knowledge, this is one of the few cases of laparoscopic cholecys-tectomy in situs inversus reported from Pakistan.9-12

This case highlights the need for careful planning of laparoscopic cholecystectomy in a known case of situs inversus totalis to avoid unforeseen complications resulting from anomalous position of abdominal viscera.

\section{PATIENTS' CONSENT:}

Consent was obtained from the patient for publishing the data related to the case.

\section{CONFLICT OF INTEREST:}

Authors declared no conflict of interest.

\section{AUTHORS' CONTRIBUTION:}

FSM, UIB, WHK: Substantially contributed to the concept or design of the work; the acquisition, analysis, or interpretation of data for the work; drafted the work and revised it critically for important intellectual content; finally approved of the version to be published; agreement to be accountable for all aspects of the work in ensuring that questions related to the accuracy or integrity of any part of the work are appropriately investigated and resolved. 
SMB, MU, SU: Drafted the work and revised it critically for important intellectual content; finally approved the version to be published; agreed to be accountable for all aspects of the work in ensuring that questions related to the accuracy or integrity of any part of the work are appropriately investigated and resolved.

\section{REFERENCES}

1. Moreli SH, Young L, Reid B, Ruttenberg H, Bamshad MJ. Clinical analysis of families with heart, midline and laterality defects. Am J Med Genet 2001; 101:388-92.

2. Borgaonkar VD, Deshpande SS, Kulkarni VV. Laparoscopic cholecystectomy and appendicectomy in situs inversus totalis: A case report and review of literature. J Minim Access Surg 2011; 7:242-5.

3. Kamitani S, Tsutamoto Y, Hanasawa K, Tani T. Laparoscopic cholecystectomy in situs inversus totalis with "inferior" cystic artery: A case report. World J Gastroenterol 2005; 11:5232-4.

4. Lochman P, Hoffmann P, Koci J. Elective laparoscopic cholecystectomy in a 75-year-old woman with situs viscerum inversus totalis. Wideochir Inne Tech Maloinwazyjne 2012; 7:216-9.

5. Campos L, Sipes E. Laparoscopic cholecystectomy in a 39-yearold female with situs inversus. J Laparoendosc Surg 1991; 1:123-5.
6. Ali MS, Attash SM. Laparoscopic cholecystectomy in a patient with situs inversus totalis: Case report with review of literature. BMJ Case Rep 2013; 2013.

7. Arya SV, Das A, Singh S, Kalwaniya DS, Sharma A, Thukral BB. Technical difficulties and its remedies in laparoscopic cholecystectomy in situs inversus totalis: A rare case report. Int J Surg Case Rep 2013; 4:727-30.

8. Alam A, Santra A. Laparoscopic cholecystectomy in situs inversus totalis. Ann Hepatobiliary Pancreat Surg 2017; 21:84-7.

9. Masood R, Samiullah, Chaudhary IA, Taimur. Laparoscopic cholecystectomy for left-sided gall bladder. J Ayub Med Coll Abbottabad 2009; 21:162-3.

10. Butt $M Q$, Chatha SS, Ghumman $A Q$, Rasheed $A$, Farooq $M$, Ahmed J. Laparoscopic cholecystectomy for left-sided gallbladder in situs inversus totalis. J Coll Physicians Surg Pak 2015; 25(Suppl 1):S22-3.

11. Din IU, Shah SFH, Ghazanfar M, Abieen ZU, Hussain M, Shah SA. Situs inversus: Open cholecystectomy and appendectomy: A literature review. J Clin Case Rep 2017; 7:1047.

12. Mehboob M, Saleem MS, Achackzai MA, Qayyum A. Laparoscopic cholecystectomy in situs inversus totalis. J Sur Pak (Int) 2007; 12:141-2. 